\title{
Cyclopropanation/Carboboration Reactions of Enynes with $B\left(C_{6} F_{5}\right)_{3}$
}

\author{
Max M. Hansmann, ${ }^{* \dagger}{ }^{\dagger}$ Rebecca L. Melen, ${ }^{\ddagger}$ Matthias Rudolph, ${ }^{\dagger}$ Frank Rominger, ${ }^{\dagger}$ Hubert Wadepohl, ${ }^{\S}$ \\ Douglas W. Stephan, ${ }^{*}, \|$ and A. Stephen K. Hashmi $*, \dagger, \perp$ \\ ${ }^{\dagger}$ Organisch-Chemisches Institut, Ruprecht-Karls-Universität Heidelberg, Im Neuenheimer Feld 270, 69120 Heidelberg, Germany \\ ${ }^{\ddagger}$ School of Chemistry, Cardiff University, Main Building, Cardiff, CF10 3AT, Cymru/Wales, U.K. \\ ${ }^{\S}$ Anorganisch-Chemisches Institut, Ruprecht-Karls-Universität Heidelberg, Im Neuenheimer Feld 270, 69120 Heidelberg, Germany \\ "Department of Chemistry, University of Toronto, 80 Saint George Street, Toronto, Ontario M5S 3H6, Canada \\ ${ }^{\perp}$ Chemistry Department, Faculty of Science, King Abdulaziz University (KAU), Jeddah 21589, Saudi Arabia
}

Supporting Information

ABSTRACT: Stoichiometric reaction of $\mathrm{B}\left(\mathrm{C}_{6} \mathrm{~F}_{5}\right)_{3}$ with $1,6-$ enynes is shown to proceed via initial cyclopropanation and formal 1,1-carboboration. Depending on the substitution on the alkene moiety, subsequent ring-opening of the cyclopropane affords either cyclopentane or cyclohexane derivatives in which the $\mathrm{C}_{6} \mathrm{~F}_{5}$ and $\mathrm{B}\left(\mathrm{C}_{6} \mathrm{~F}_{5}\right)_{2}$ adopt a 1,4-positioning. Mechanistically, this transformation involves $\pi$-activation of the alkyne moiety, which triggers cyclopropanation, followed by carboboration. Both the cyclopropanation and subsequent ring-opening are shown to be stereospecific. Both cyclopropanation and 1,4-carboborated products were employed as Lewis acid components in frustrated Lewis pair activation of $\mathrm{H}_{2}$ and $\mathrm{CO}_{2}$.

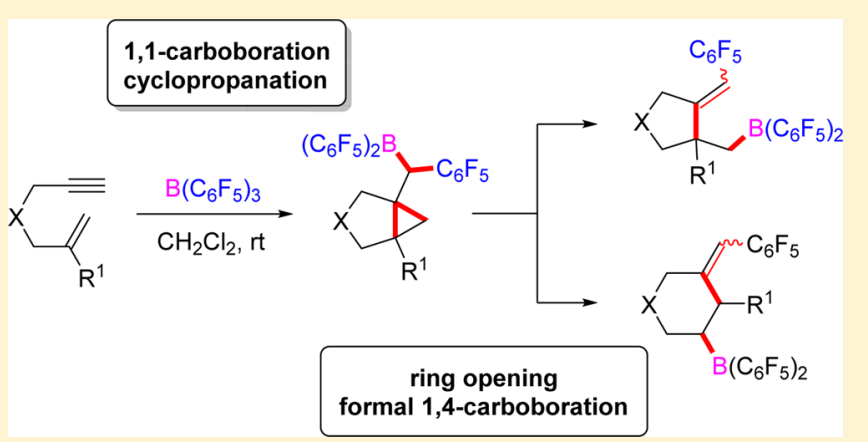

carboboration reaction. Since these findings the reactions of $\mathrm{B}\left(\mathrm{C}_{6} \mathrm{~F}_{5}\right)_{3}$ with $\pi$-bonds has been widely exploited in 1,1carboboration. ${ }^{24,28-43}$ An elegant report by Ingleson described a metal-free route to 1,2-carboborations of alkynes using Lewis acidic boranes. ${ }^{44}$ More recently, Bourissou and co-workers have described a related 1,2-carboboration using a borenium reagent, ${ }^{45}$ while we have reported 1,2-carboborations of allenyl ketones and esters. ${ }^{46}$ Erker and co-workers also reported the reaction of $\mathrm{B}\left(\mathrm{C}_{6} \mathrm{~F}_{5}\right)_{3}$ with simple conjugated enynes, affording both carboboration and cyclization to give a facile route to a 2,3-dihydroborole. ${ }^{47,48}$ In related work, Ingleson has described the reactions of 1,6 hexadiynes with $\mathrm{BCl}_{3}$ to give electrophilic borylative cyclization products. ${ }^{49}$

In seeking to extend the reactivity of $B\left(\mathrm{C}_{6} \mathrm{~F}_{5}\right)_{3}$ in further reactions with enynes, targeting new avenues to cyclization, we noted that for transition metal mediated cyclizations of enynes, a number of experimental and theoretical studies debated the nature of key intermediates, suggesting that cyclopropane, cyclobutane, cationic, radical or carbene type intermediates may be involved. ${ }^{50-56}$ In this manuscript we explore the reactivity of a series of enynes with $\mathrm{B}\left(\mathrm{C}_{6} \mathrm{~F}_{5}\right)_{3}$, demonstrating the initial products are derived from cyclopropanation and formal 1,1 carboboration. Depending on substitution, further ring-opening of the cyclopropane affords cyclopentane or cyclohexane

Received: September 2, 2015

Published: November 18, 2015 
derivatives which presents net 1,4-carboboration products. The subsequent utility of these resulting products in FLP activation of $\mathrm{H}_{2}$ and $\mathrm{CO}_{2}$ are also probed.

\section{RESULTS AND DISCUSSION}

Reaction of 1,6-enyne $\mathbf{1 a}$ in a 1:1 stoichiometric ratio with $\mathrm{B}\left(\mathrm{C}_{6} \mathrm{~F}_{5}\right)_{3}$ results in a rapid $(<10 \mathrm{~min})$ and very clean transformation, generating a 3.1:1 mixture of two diastereomers as evidenced by in situ ${ }^{1} \mathrm{H} /{ }^{19} \mathrm{~F} /{ }^{13} \mathrm{C}$ NMR spectroscopy. 2DNMR studies allowed the clear assignment of the obtained isomeric mixtures of the diastereomers to be the 1,1carboborated product $\mathbf{2}$ which contains a cyclopropane unit (Scheme 1). The ${ }^{11} \mathrm{~B}$ NMR spectrum shows a broad resonance

Scheme 1. Boron Mediated Cyclopropanation Reactions of 1,6-Enynes

(i)
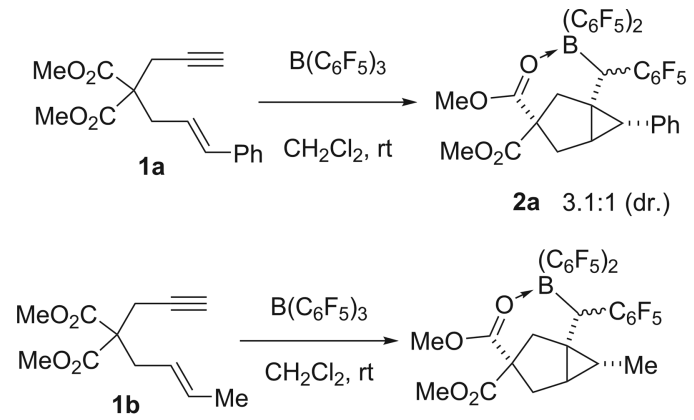

2b $3.2: 1$ (dr.)

(iii)

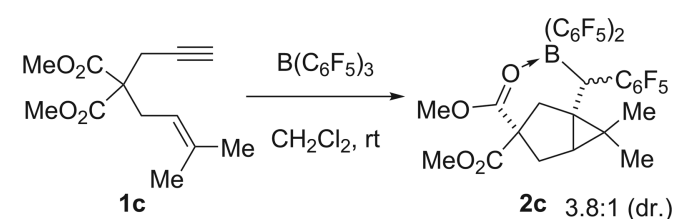

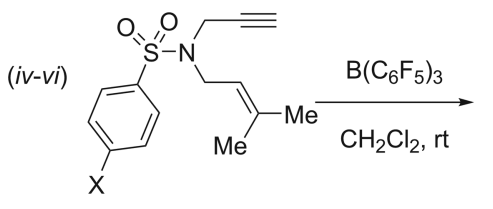

$X=\operatorname{Me} 1 \mathrm{~d}, \mathrm{Br} 1 \mathrm{e}, \mathrm{NO}_{2} 1 \mathrm{f}$

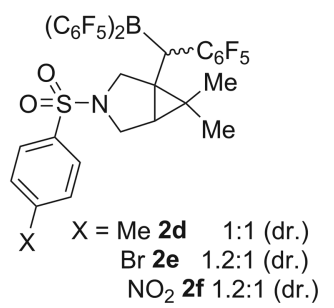

at $\delta \approx 3 \mathrm{ppm}$, characteristic of an intramolecular Lewis acid/ base adduct suggesting an interaction of the $\mathrm{B}$ with a carbonyl fragment similar to that observed in our previous studies. ${ }^{46}{ }^{19} \mathrm{~F}$ NMR spectroscopy shows two sets of resonances at $-132.3 /$ $140.3 \mathrm{ppm}\left(o-\mathrm{C}_{6} \mathrm{~F}_{5}\right),-154.5 /-160.2 \mathrm{ppm}\left(p-\mathrm{C}_{6} \mathrm{~F}_{5}\right)$ and $-163.1 /-165.6 \mathrm{ppm}\left(m-\mathrm{C}_{6} \mathrm{~F}_{5}\right)$. These are attributed to two distinct $\mathrm{C}_{6} \mathrm{~F}_{5}$ groups resulting from a carboboration reaction. Interestingly, the ${ }^{13} \mathrm{C}$ NMR spectrum reveals a ${ }^{13} \mathrm{C}-{ }^{19} \mathrm{~F}$ through space coupling indicated by the resonance for $\mathrm{C}^{2}$ which appears as a triplet at $43.7 \mathrm{ppm}$ with a coupling constant of $8.0 \mathrm{~Hz}$ (Figure 1) at room temperature. Similar through space couplings have been previously observed. ${ }^{57,58}$ This is assumed to result from the close proximity of the $\mathrm{C}-\mathrm{H}$ bond with the ortho-fluorine atoms on the $\mathrm{C}_{6} \mathrm{~F}_{5}$ ring. This is consistent with the observation of five ${ }^{19} \mathrm{~F}$ NMR signals for each $\mathrm{C}_{6} \mathrm{~F}_{5}$ ring in $2 \mathrm{a}$ at $-80{ }^{\circ} \mathrm{C}$ (Figure $\mathrm{S} 1$; SI) and further supported by ${ }^{19} \mathrm{~F} /{ }^{1} \mathrm{H}$ HETCOSY and ${ }^{13} \mathrm{C}$ NMR studies at -80 ${ }^{\circ} \mathrm{C}$ revealing the correlation of the $\mathrm{F}$ atom with the $\mathrm{C}^{2}-\mathrm{H}$ bond (Figure S2, S4). The structural connectivity was confirmed by

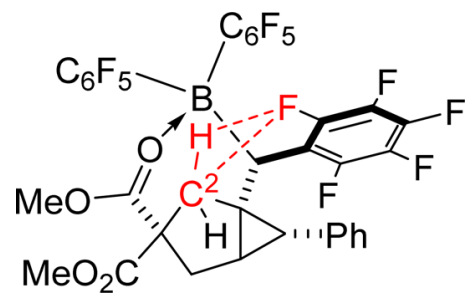

Figure $1 .{ }^{13} \mathrm{C} /{ }^{19} \mathrm{~F}$ through space coupling.

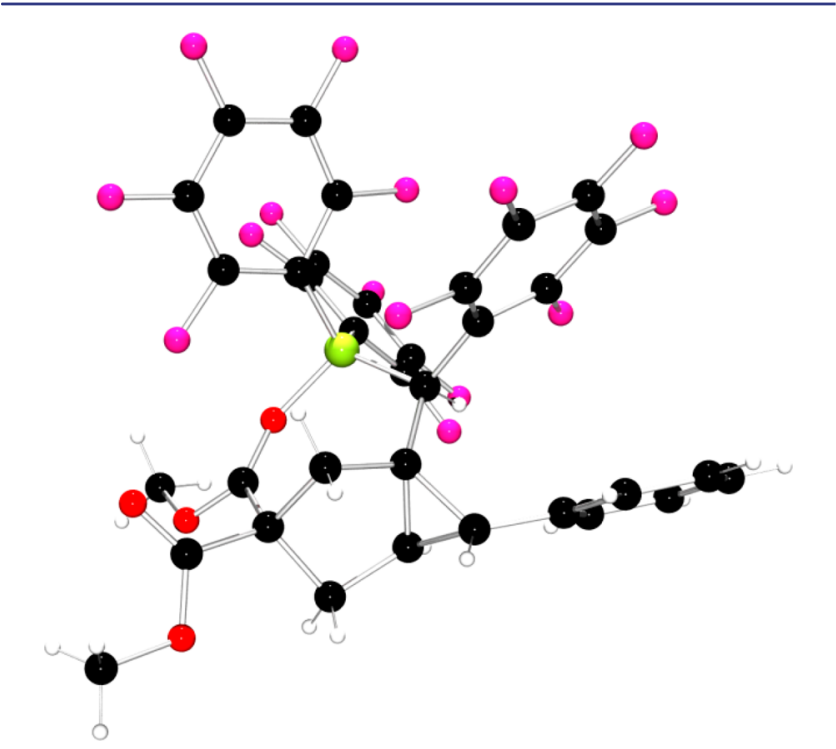

Figure 2. Solid-state molecular structure of $2 \mathrm{a}$. C: Black, N: blue, O: red, F: pink, B: yellow-green, $\mathrm{H}$ : white.

an X-ray diffraction study (Figure 2) revealing intramolecular coordination of the carbonyl moiety to the Lewis-acidic boron center to generate the tricyclic 7/5/3- membered ring system. In addition, the solid-state structure exhibits a short $\mathrm{C}^{2} \cdots \mathrm{F}$ distance of $2.820 \AA$, typical for through space ${ }^{19} \mathrm{~F} /{ }^{13} \mathrm{C}$ interactions previously observed. ${ }^{57,58}$

The formation of $\mathbf{2 a}$ proceeds with the construction of $3 \mathrm{C}-$ $\mathrm{C}$ bonds affording 5 new stereocenters. However, despite the molecular complexity generated in this reaction, $\mathbf{2 a}$ forms selectively with the phenyl ring in the endo position with respect to the alkylborane on the cyclopropane ring. In the reaction, we only ever observe two diasteromers being formed as a 3:1 mixture at the $\alpha$-position to boron. Nonetheless, the major diastereomer could be easily separated by fractional crystallization giving clean product on a preparative scale. This reaction stands in stark contrast to typical 1,1-carboboration reactions of alkynes which afford vinylboranes. ${ }^{29}$

We were encouraged by this initial result and decided to probe related cyclopropanation reactions. Treatment of 1,6enynes with methyl- (1) $)$ or dimethyl-substituted (1c) olefins with stoichiometric quantities of $\mathrm{B}\left(\mathrm{C}_{6} \mathrm{~F}_{5}\right)_{3}$ cleanly gave diastereomeric mixtures of the cyclopropanation products $\mathbf{2 b}$ and $2 \mathrm{c}$ in a ratio of ca. 3.2:1 and 3.8:1, respectively (Scheme 1). Interestingly, $2 \mathrm{c}$ proved to be remarkably stable even at $60{ }^{\circ} \mathrm{C}$ for several days. In the case of the cyclopropanation product $\mathbf{2 b}$, a single crystal X-ray diffraction study confirmed the structural assignment (see SI) and reveals that coordination of the ester carbonyl moiety to the Lewis acidic boron center yields a sevenmembered ring comparable to that observed for $\mathbf{2 a}$. 
In a similar fashion the 1,6-enynes containing a para-sulfonylamide $(\mathbf{1} \mathbf{d}-\mathbf{f})$ react with $\mathrm{B}\left(\mathrm{C}_{6} \mathrm{~F}_{5}\right)_{3}$ rapidly and highly selectively to give the corresponding cyclopropanation/carboboration products $(\mathbf{2 d}-\mathbf{f})$. In contrast to $\mathbf{2 a}-\mathbf{c},{ }^{11} \mathrm{~B}$ NMR spectroscopy showed broad peaks around $\delta \approx 77 \mathrm{ppm}$, consistent with a trigonal planar boron center. In these cases, while in situ NMR spectroscopy indicated a quantitative conversion to the products, diasteromerically pure $r a c-(R, R, S)-\mathbf{2 d - f}$ were obtained on a preparative scale by fractional crystallization in yields of $43 \%(\mathbf{2 d}), 41 \%$ (2e) and 39\% (2f). While these trigonal planar boron species were challenging to crystallize, single crystals of $\mathbf{2} \mathbf{d}$ were isolated and X-ray data affirmed the formulation (Figure 3) and the presence of a three coordinate

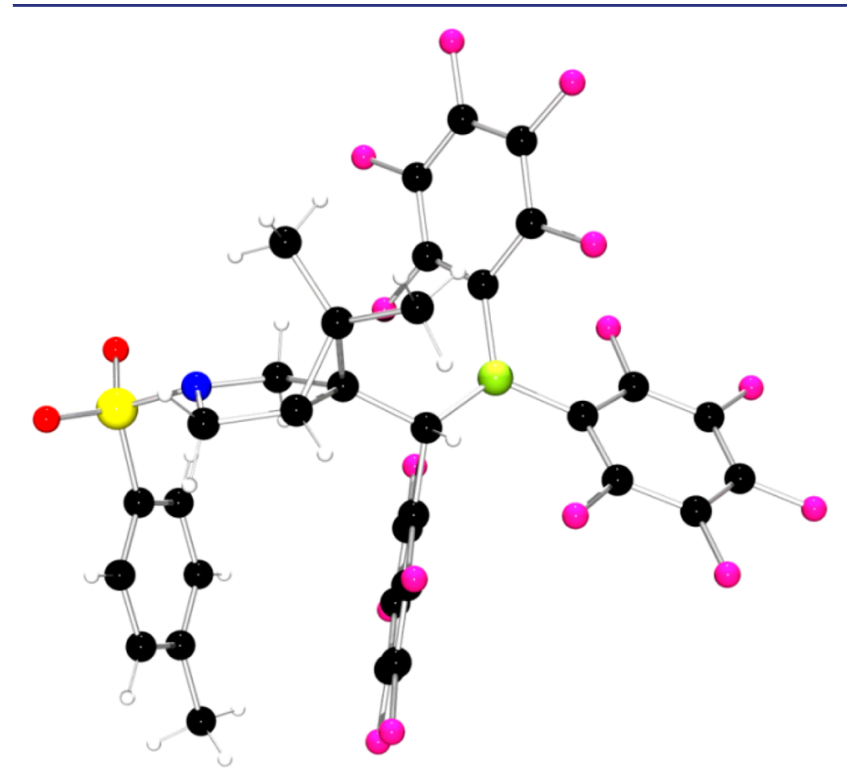

Figure 3. Solid-state molecular structure of 2d. C: Black, N: blue, O: red, S: yellow, F: pink, B: yellow-green, H: white.

boron center. It is interesting to note that the diasteromeric ratios of the products derived from these sulfonamide derived 1,6-enynes $(\mathbf{1} \mathbf{d}-\mathbf{f})$ were $1: 1$. This stands in contrast to the products derived from malonic acid 1,6-enynes $(\mathbf{1 a - c})$ and suggests the selectivity in this reaction might involve a chelate assisted carboboration mechanism in which the coordination of the Lewis acidic borane to the Lewis basic ester functionality directs the reaction yielding one diastereoisomer in preference to the other.

The corresponding reaction of the 1,6-enyne $1 \mathrm{~g}$ featuring a gem-disubstituted alkene, with $\mathrm{B}\left(\mathrm{C}_{6} \mathrm{~F}_{5}\right)_{3}$ proceeds cleanly in $<3 \mathrm{~h}$ to give quantitative formation of a $1: 1.5$ diasteromeric mixture of a new product. 2D NMR studies indicated the generation of the unexpected 1,4-carboboration product $2 \mathrm{~g}$ as a mixture of $E$ and $Z$ isomers depending upon the position of the $\mathrm{C}_{6} \mathrm{~F}_{5}$ group on the newly generated alkene fragment (Scheme 2 ). The assignment of the $E$ or $Z$ diastereomers were confirmed by NOE measurements as well as ${ }^{13} \mathrm{C}$ measurements in which only the E-compound exhibited a through-space ${ }^{13} \mathrm{C} /{ }^{19} \mathrm{~F}$ coupling ${ }^{59}$ between the ortho- $\mathrm{C}_{6} \mathrm{~F}_{5}$ groups and the proximal methylene proton in the cyclopentane ring (see SI). A single crystal X-ray diffraction study of the minor (E)-isomer $\mathbf{2 g}$ confirmed the assigned connectivity and the net 1,4- nature of the carboboration product (Figure 4). In addition, the X-ray crystal structure clearly depicts the bicyclic nature of $\mathbf{2 g}$ which comprises a cyclopentane ring and a seven membered ring
Scheme 2. 1,4-Carboboration Reactions of 1,6-Enynes

(i)

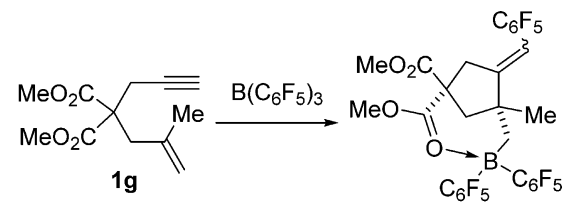

2g 1:1.5 (E:Z)

(ii-iii)

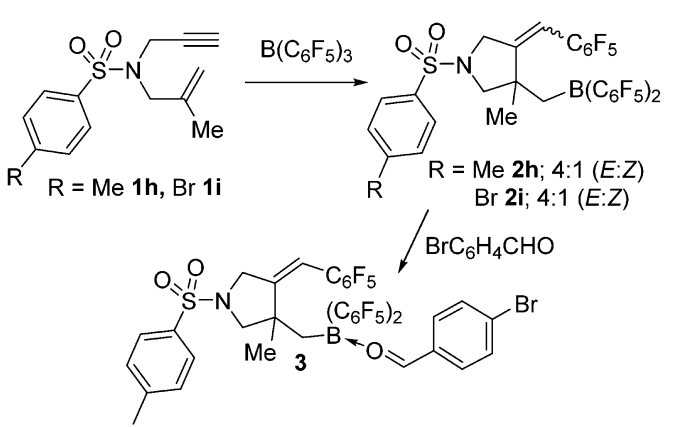

(iv)

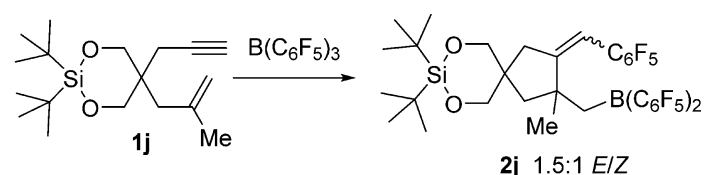

$(v-v i)$

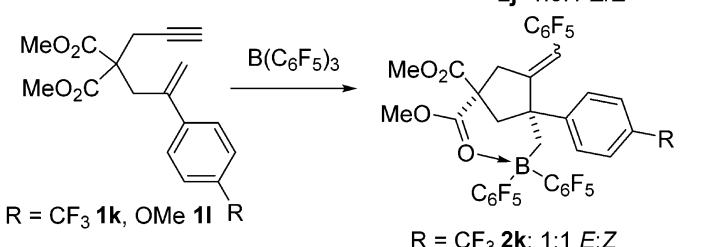

(vii)

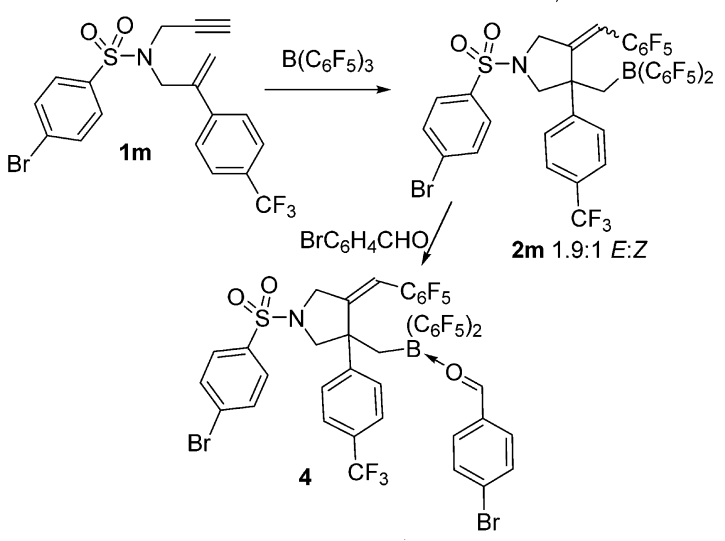

formed by coordination of the ester fragment to boron. The structure also reveals the short F-C separation of 2.90(1) $\AA$ between an ortho-F and the methyl substituent on the cyclopentane ring, consistent with the observed NOE and ${ }^{13} \mathrm{C}$ NMR data. It is important to note that the formation of $2 \mathrm{~g}$ is an unusual example of carboboration ultimately affording 1,4positioning of the boron and fluoroarene fragments. Very recently, a net 1,4-chloroboration has been reported by Ingleson from the reaction of $\mathrm{BCl}_{3}$ with the terminal diyne, 1,6-heptadiyne. ${ }^{49}$

Analogous reactivity of enynes $\mathbf{1 h} \mathbf{- i}$ containing sulfonamide functionalities, the 1,6-cyclic silyl protected diol enyne derivative $\mathbf{1 j}$ and the aryl-substituted enynes $\mathbf{1 k}-\mathbf{m}$ (Scheme 2) afforded the related $E / Z-1,4$-carboboration products $\mathbf{2 h}-\mathbf{m}$. ${ }^{11} \mathrm{~B}$ NMR data were consistent with either three-coordinate boron species which gave a broad peak at $\delta>60 \mathrm{ppm}(\mathbf{2 h - 2 j}$, 

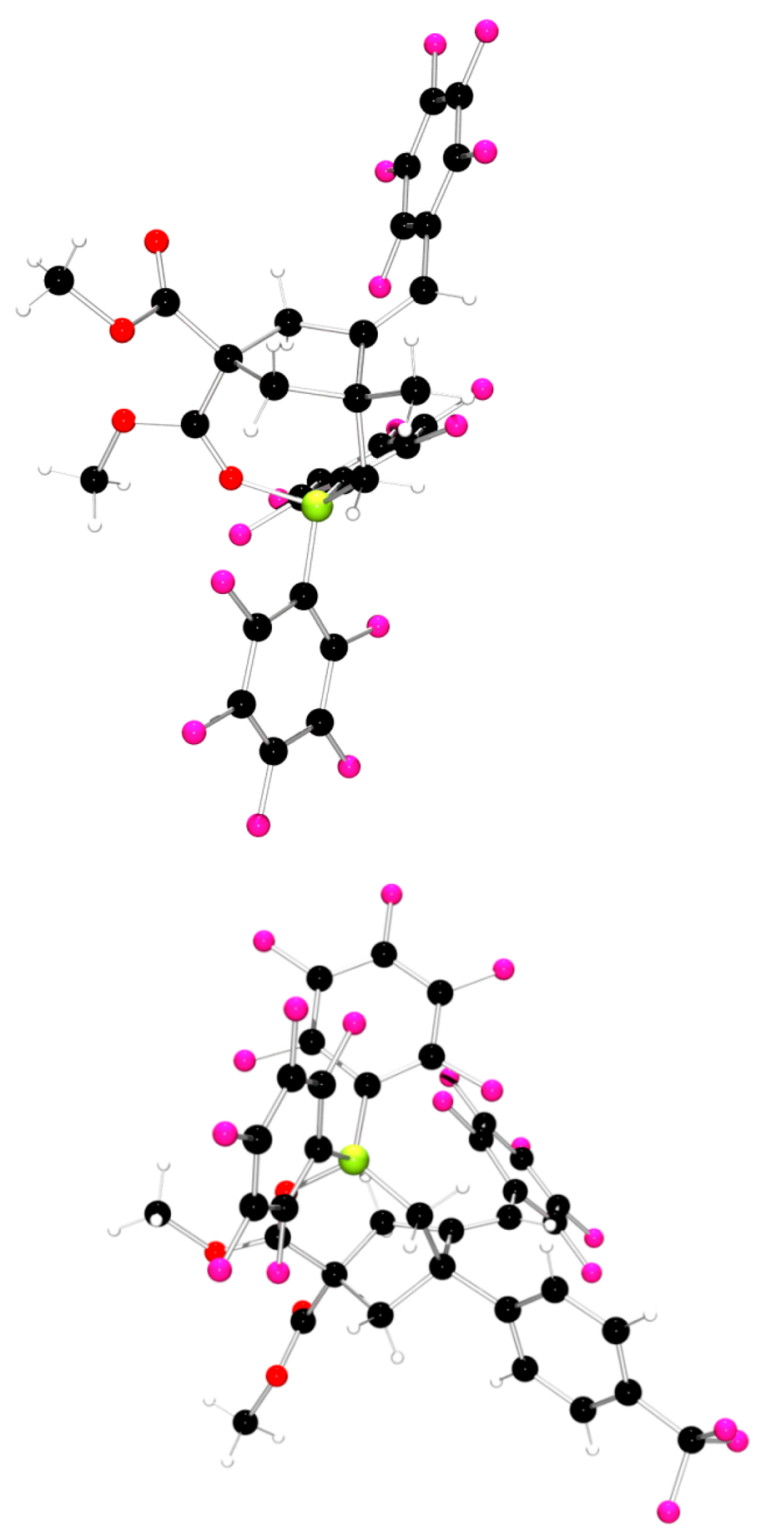

Figure 4. Solid-state molecular structures of compounds $2 \mathrm{~g}$ and $\mathbf{2 k}$. C: Black, N: blue, O: red, F: pink, B: yellow-green, H: white.

$\mathbf{2 m}$ ) or four-coordinate compounds with a more sharp peak at $\delta \approx 27 \mathrm{ppm}(2 \mathrm{k}, 2 \mathrm{l})$. While the reaction of the para-brosyl amide derivative $2 \mathbf{i}$ could be fractionally crystallized to give the diasteromerically pure 1,4-carboborated product $(E)-2 \mathbf{i}$, the para-tosyl amide analog $2 \mathrm{~h}$ proved to be more resistant to crystallization. However, the corresponding para-bromobenzaldehyde $\mathbf{3}$ adduct derived from $\mathbf{2 h}$ was readily isolated and showed a sharp singlet in the ${ }^{11} \mathrm{~B}$ NMR spectrum at $-8.5 \mathrm{ppm}$. In the case of $\mathbf{2 k}$ and $\mathbf{2 l}, \mathrm{X}$-ray diffraction confirmed the nature of the 1,4-carboboration products (Figure 4 and SI). In the reaction of enyne $1 \mathrm{~m}$, the 1,4 -carboboration product $2 \mathrm{~m}$ was formed as a 1:1.8 mixture of $E / Z$-isomers. In this case, $\mathrm{X}$-ray data was obtained for the para-bromobenzaldehyde adduct of the $(E$ )-isomer of $\mathbf{2 m}, \mathbf{4}$ (Figure 5).

Further insight into the selectivity of these cyclopropanation reactions with different olefin regioisomers was probed employing the enynes $1 n$ and 10 which are identical with the exception of the geometry (cis or trans) of the alkene. The reaction of the trans-olefin 1 n gave a 1:1.5 mixture of cyclopropanation products 2n (Scheme 4). Although 2n

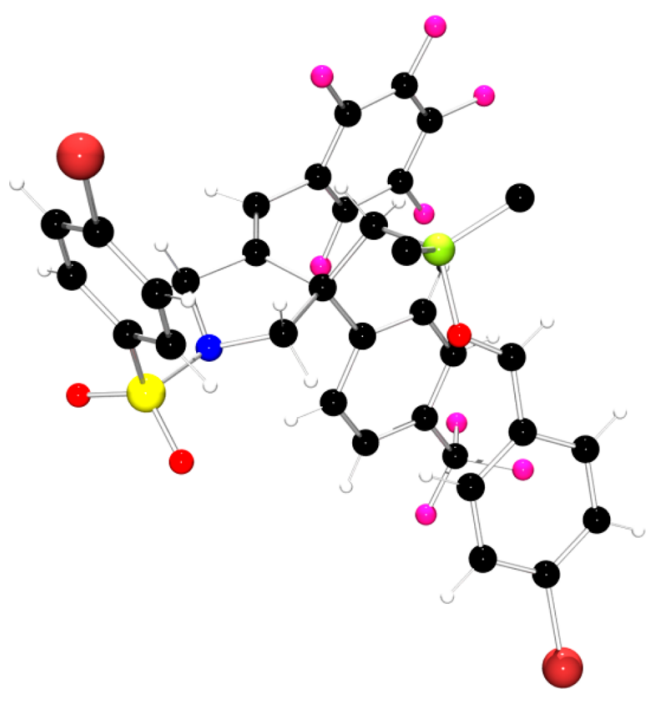

Figure 5. Solid-state molecular structure of $4\left(\mathrm{C}_{6} \mathrm{~F}_{5}\right.$ groups on boron removed for clarity). C: Black, N: blue, O: red, F: pink, Br: scarlet, S: yellow, B: yellow-green, $\mathrm{H}$ : white.

formed as two diastereoisomers, one could be selectively isolated and fully characterized at low temperatures. However, it should be noted that this compound was unstable in solution at room temperature and showed an unselective reaction yielding a mixture of cyclopropanation ring-opening products.

In contrast to the reaction of the E-olefin $1 n$ with $\mathrm{B}\left(\mathrm{C}_{6} \mathrm{~F}_{5}\right)_{3}$, the equivalent reaction of the $Z$-configured enyne substrate $\mathbf{1 p}$ afforded two 1,4-carboboration products with no evidence for cyclopropanation. However, 2D NMR analysis were not consistent with the expected mixture of $E / Z$-isomers as seen previously for $\mathbf{1 g}-\mathbf{m}$ (Scheme 2) but rather a 1:1 mixture of the 1,4-carboboration products based on 5-membered (2o) and a new 1,4-carboboration product based upon a 6-membered

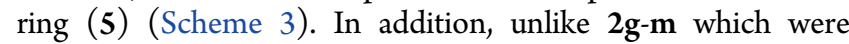
formed as a mixture of $E / Z$ isomers, it should be highlighted that both compounds 20 and 5 were formed as single

Scheme 3. Cyclopropanation and 1,4-Carboboration of E/ZOlefin Derived Enynes
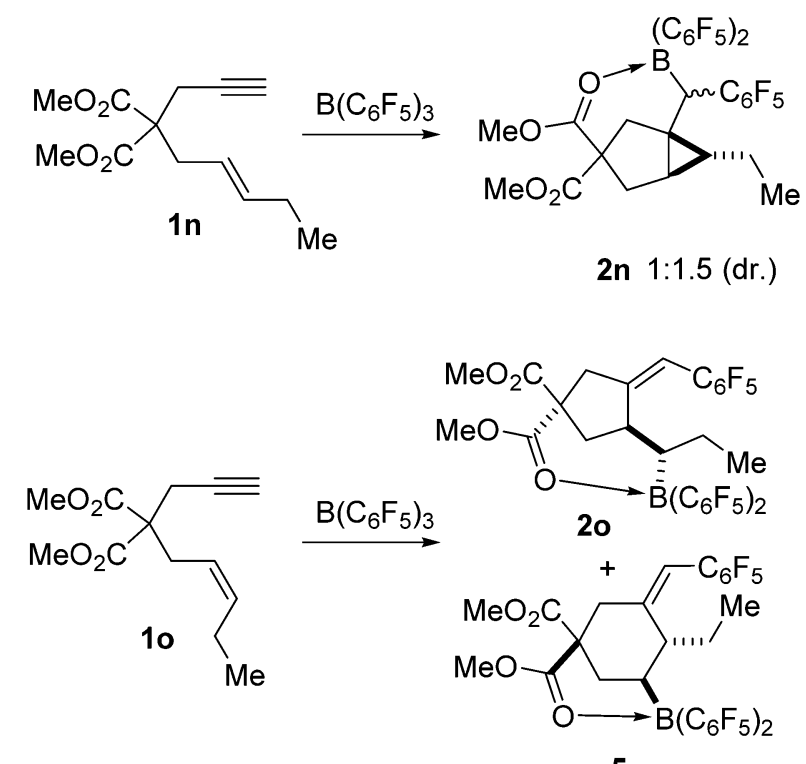

5 
diastereomers. While $\mathbf{5}$ was found to be thermally stable, 20 decomposes in solution at room temperature. The formulations of the two products were confirmed by solid-state structure determinations (Figure 6) which show intramolecular coordi-

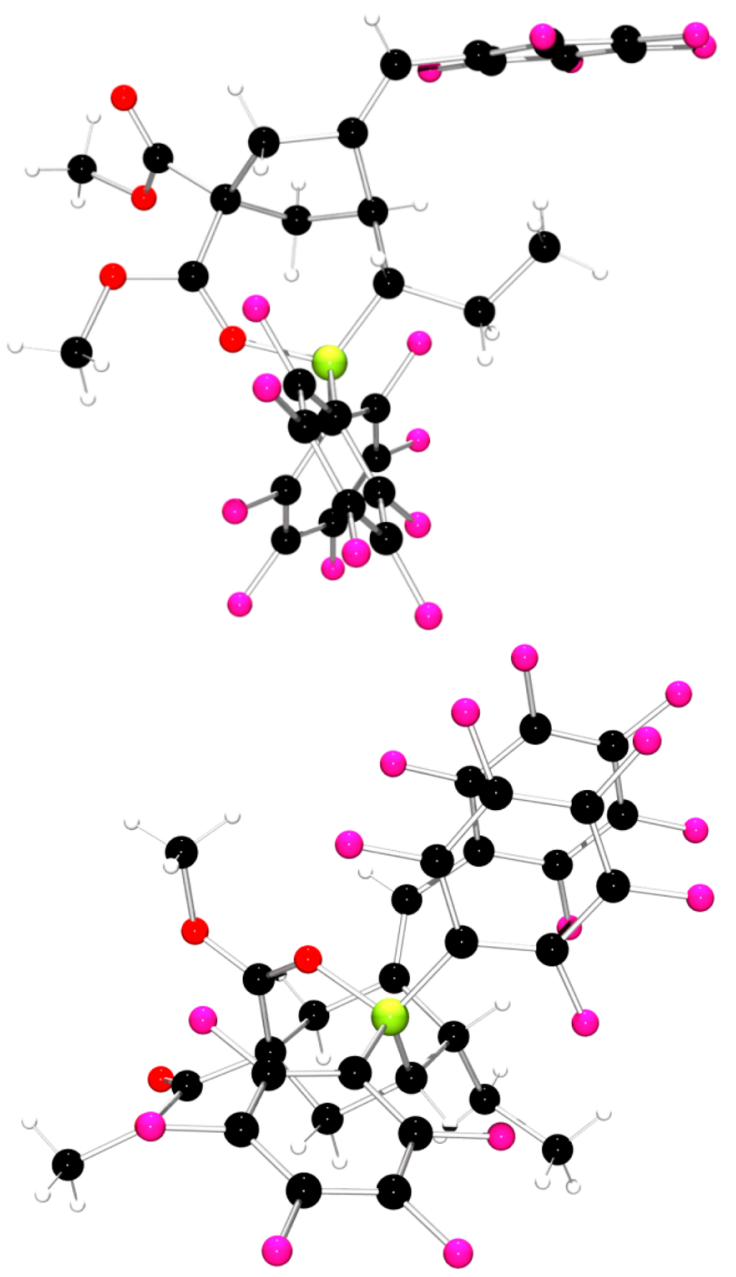

Figure 6. Solid-state molecular structures of 20 and 5. C: Black, N: blue, O: red, F: pink, B: yellow-green, $\mathrm{H}$ : white.

nation of the ester oxygen atom to the Lewis acidic borane. Based on the reactivity described above for $\mathbf{1 g}-\mathbf{m}$, the formation of $2 \mathrm{o}$ was expected, however, the formation of the 6-membered compound 5 represents a new pathway for the cyclopropane opening mechanism. The differing reaction pathways for the $E /$ $Z$-olefin configured enynes confirmed the stereospecific nature of the cyclopropanation and ring-opening processes. Furthermore, these observations exclude a radical mechanism and preclude conformational equilibration of the intermediates.

Following these studies, the reactions of the monosubstituted terminal alkene derived precursors $\mathbf{1 p}$ and $\mathbf{1 q}$ with $\mathrm{B}\left(\mathrm{C}_{6} \mathrm{~F}_{5}\right)_{3}$ were probed. These proceed less cleanly than previous examples, giving mixtures of carboboration products. Nonetheless, in the case of $1 \mathrm{p}$, subsequent to the reaction with $\mathrm{B}\left(\mathrm{C}_{6} \mathrm{~F}_{5}\right)_{3}$ addition of water gave single crystals of the 1,4carboboration product 6 as a water adduct which was confirmed by solid-state structure determination (Scheme 4, see SI). In contrast, the reaction of $\mathbf{1 q}$ with $\mathrm{B}\left(\mathrm{C}_{6} \mathrm{~F}_{5}\right)_{3}$ afforded the six-membered cyclohexane derived 1,4-carboboration product 7 as an intramolecular chelate (Scheme 4, Figure 7). Thus, while the reactions of substituted enynes are largely
Scheme 4. Carboboration Reactions with Terminal Olefin Derived Enynes
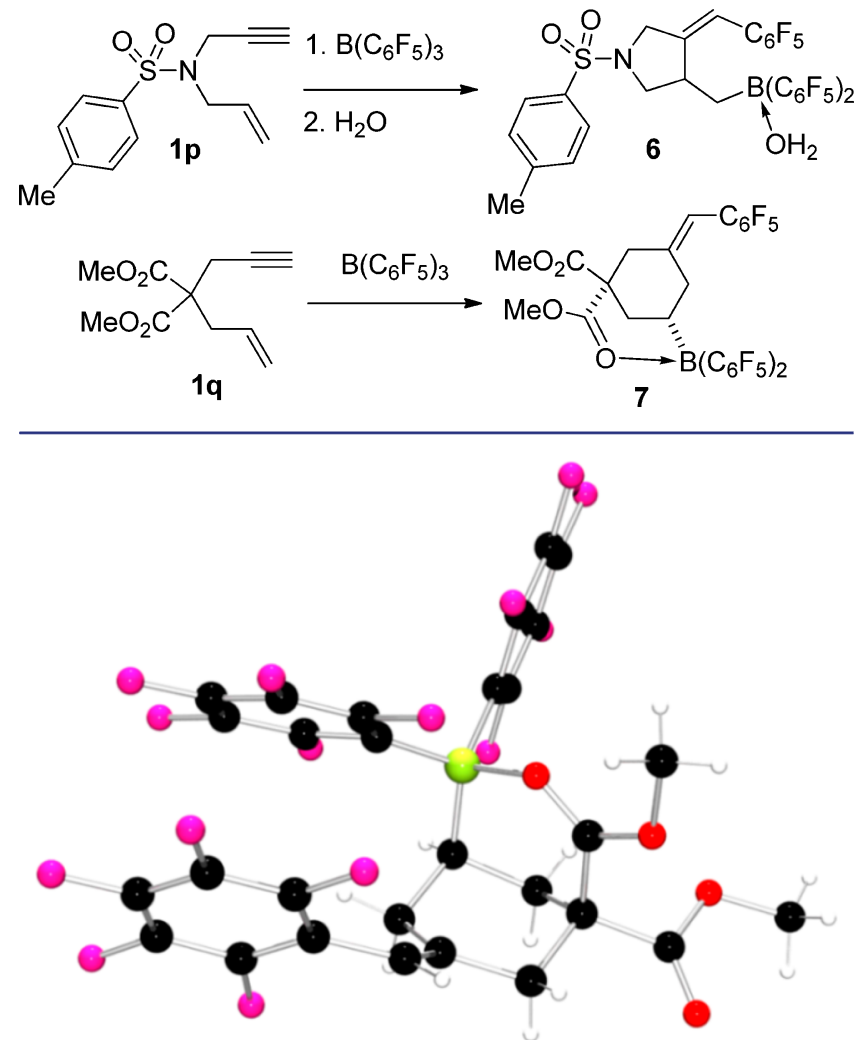

Figure 7. Solid-state molecular structure of 7. C: Black, N: blue, O: red, F: pink, B: yellow-green, H: white.

selective in the products generated (cyclopropanation vs carboboration), the unsubstituted alkene fragments afford rather unselective reactions.

Mechanistic Considerations. In order to understand the outcomes of these cyclopropanation/carboboration reactions, mechanistic studies were undertaken. Time dependent multinuclear NMR studies of the reaction of 1,6-enyne $1 \mathrm{~m}$ with $\mathrm{B}\left(\mathrm{C}_{6} \mathrm{~F}_{5}\right)_{3}$ revealed the formation of two intermediates $2 \mathbf{m}^{\prime}$ and $2 \mathbf{m}^{\prime \prime}$ in a mixture of diastereoisomers. These species gave rise to ${ }^{1} \mathrm{H}$ NMR signals at 1.49 and $1.12 \mathrm{ppm}\left(\mathbf{2 m}^{\prime}\right)$, and 1.40 and $0.70 \mathrm{ppm}\left(2 \mathrm{~m}^{\prime \prime}\right)$ which could be assigned to the characteristic cyclopropane protons showing the formation of the two corresponding diastereomeric cyclopropanation products (Scheme 5). While the cyclopropanation intermediates $\mathbf{2} \mathbf{m}^{\prime}$ and $\mathbf{2} \mathbf{m}^{\prime \prime}$ are formed rapidly, the rate of subsequent ringopening for each diastereomer to give (E/Z)-2m differs significantly. Kinetic data obtained from time dependent ${ }^{1} \mathrm{H} /{ }^{19} \mathrm{~F}$ NMR analysis (Figure S5, SI) shows that $2 \mathbf{m}^{\prime \prime}$ undergoes ring-opening to form $(Z)-\mathbf{2 m}$ more rapidly than $\mathbf{2} \mathbf{m}^{\prime}$, resulting in a changing $E / Z$ ratio of $\mathbf{2 m}$ over the course of the reaction. Ultimately this affords a ratio of 1.9:1 with the major isomer being (E)-2m (Figure 8). The differing rates of ring-opening are consistent with a consideration of the stereochemistry of the transition state in which a cyclopropane orbital interacts with the unoccupied p-orbital at boron. Steric repulsion of aryl $/ \mathrm{C}_{6} \mathrm{~F}_{5}$ groups (Figure 9) are expected to slow down ring-opening to form the $(E)-\mathbf{2 m}$ isomer.

Further support for the proposition of a cyclopropane intermediate was provided by the reaction of the enyne $1 \mathbf{r}$ with 
Scheme 5. 1,4-Carboboration Reaction Pathway via Cyclopropane Intermediates

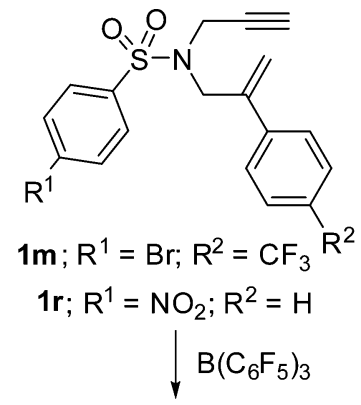<smiles>[R]c1ccc(C23CN(S(=O)(=O)c4ccc([R])cc4)CC2(C([R17])C(F)(F)F)C3)cc1</smiles>

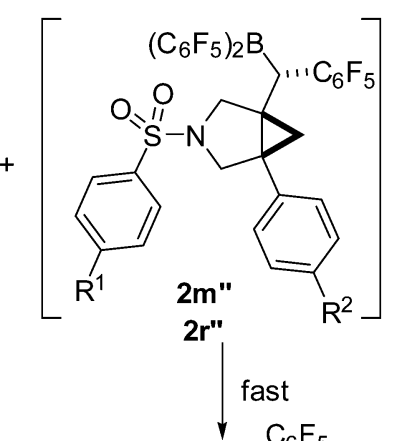<smiles>[R]c1ccc(C2(CBr)CN(S(=O)(=O)c3ccc([R16])cc3)C/C2=C/C(F)(F)F)cc1</smiles><smiles>[R]c1ccc(C2(CC(C)(C(F)(F)F)C(F)(F)F)CN(S(=O)(=O)c3ccc([R2])cc3)CC2=CC(F)(F)F)cc1</smiles>

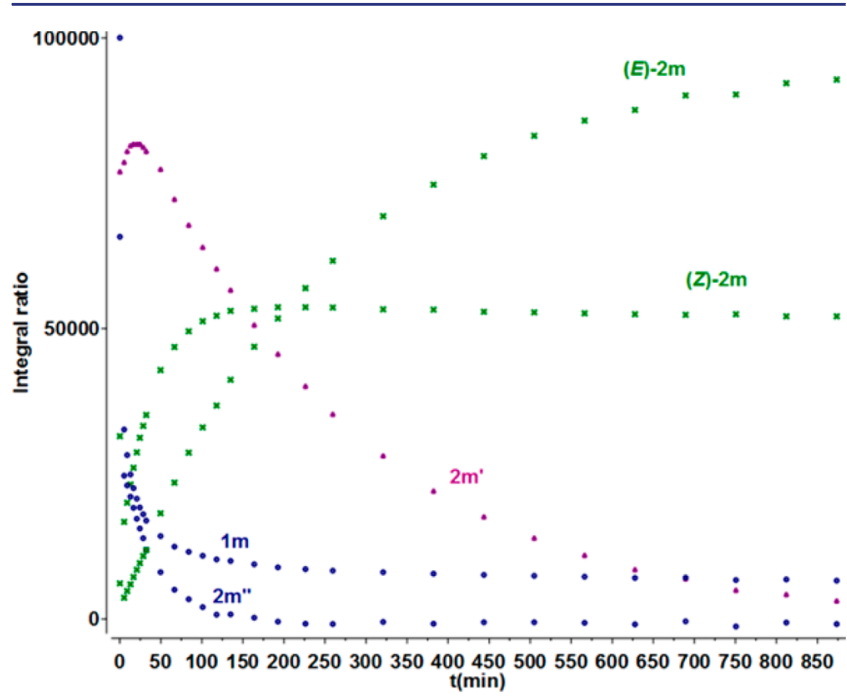

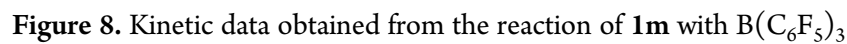
determined by ${ }^{1} \mathrm{H}$ NMR integration.

$\mathrm{B}\left(\mathrm{C}_{6} \mathrm{~F}_{5}\right)_{3}$ (Scheme 5). In this case, both colorless and orange crystals could be obtained from the reaction. The orange crystals proved to be the 1,4-carboboration product $(Z)-2 \mathbf{r}$ containing a trigonal planar Lewis acidic boron as confirmed by $\mathrm{X}$-ray diffraction (Figure 10). Conversely, low temperature 2D NMR studies of the colorless crystals confirmed it to be the cyclopropane intermediate $\mathbf{2} \mathbf{r}^{\prime}$. The conversion of $\mathbf{2} \mathbf{r}^{\prime}$ to $(E)-\mathbf{2 r}$ could be observed by warming the sample of $2 \mathbf{r}^{\prime}$ to room

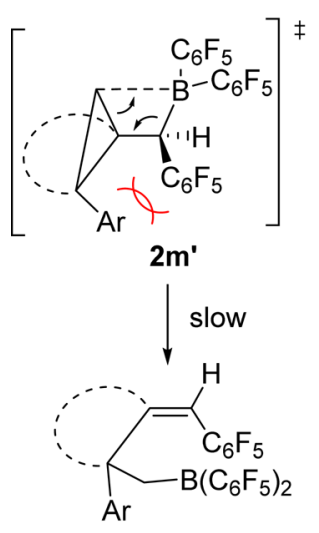

$(E)-2 m$

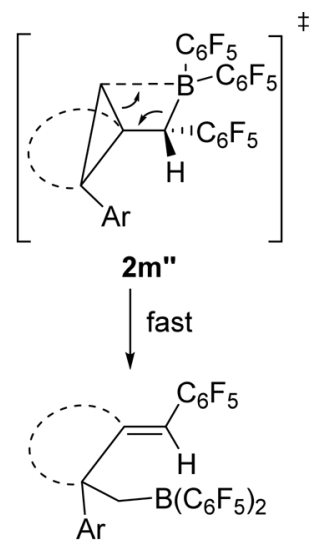

(Z)-2m
Figure 9. Stereochemical rationale for differential rates of cyclopropane opening.

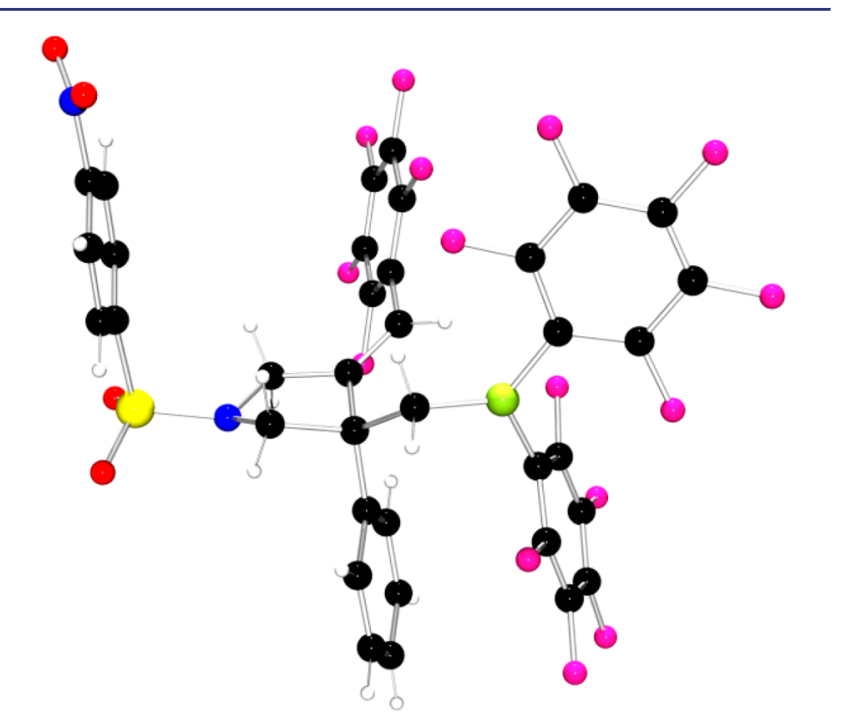

Figure 10. Solid-state molecular structure of 2r. C: Black, N: blue, O: red, F: pink, S: yellow, B: yellow-green, $\mathrm{H}$ : white.

temperature (see Figure S6, SI) confirming that the cyclopropanation product is formed en route to the 1,4carboboration product. (E)-2r was found to be configurationally stable and did not undergo thermal isomerization to $(Z)-2 \mathbf{r}$.

Overall the enyne $/ \mathrm{B}\left(\mathrm{C}_{6} \mathrm{~F}_{5}\right)_{3}$ reaction can be considered as arising through the initial Lewis acid alkyne activation (I, Scheme 6) analogous to that previously described for propargyl esters. ${ }^{21}$ While such $\pi$-alkyne boron complexes have not been observed, weak van der Waals interactions of boranes with olefins have been detected. ${ }^{60}$ The alkyne activation triggers the nucleophilic attack of the alkene prompting the 5-exo cyclization (II) and subsequent cyclization to the cyclopropyl cation (III). The experiments performed with Z- and Econfigured alkenes indicate a concerted cyclopropanation mechanism without the stepwise formation of II. The positive charge on the $\alpha$-carbocation in III prompts migration of a $\mathrm{C}_{6} \mathrm{~F}_{5}$ group affording the cyclopropanation product as a mixture of diastereoisomers in which there has been a net 1,1carboboration reaction. The subsequent cyclopropane ringopening reaction to give the $E / Z$ five- or six-membered ring products depends markedly on the nature of the substitution as seen for the reactions of $\mathbf{1 g}-1 \mathrm{~s}$ with $\mathrm{B}\left(\mathrm{C}_{6} \mathrm{~F}_{5}\right)_{3}$. Thus, while mono- or disubstitution in 7-position on the alkene moiety 
Scheme 6. Proposed Mechanism for the Cyclopropanation/ Carboboration Reactions
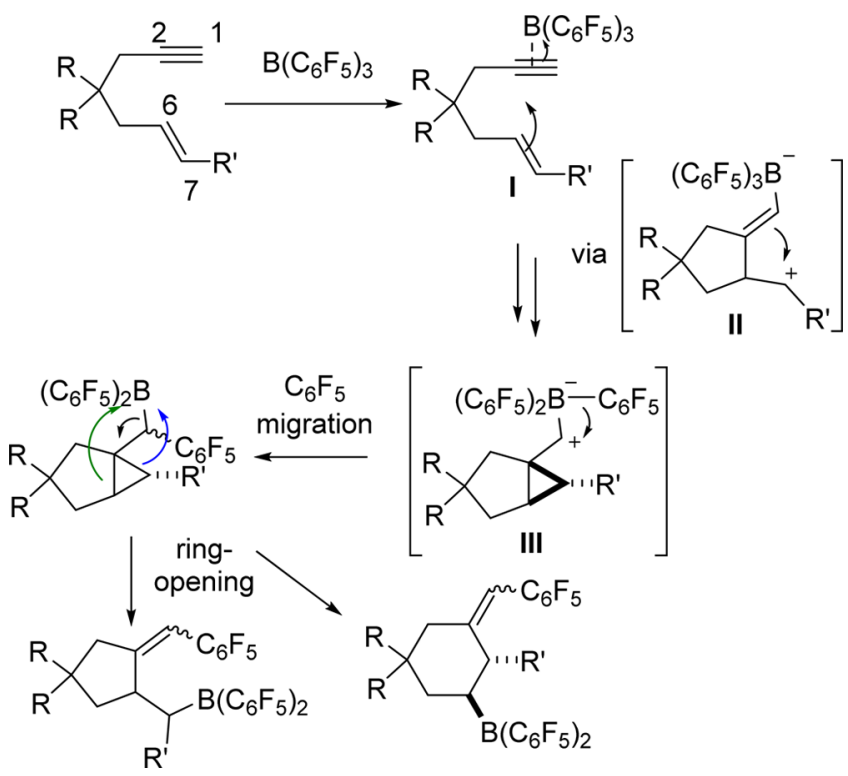

affords stable cyclopropyl compounds (1a-1h), the absence of this substitution prompts stereospecific ring-opening affording either cyclopentane or cyclohexane derived alkylboranes (Scheme 6). It is noteworthy that there is precedence for methylcyclopropane boron derivatives undergoing ring-openings, ${ }^{61}$ and indeed such compounds have been used in homoallylation reactions. ${ }^{62}$ Similarly, cyclopropanes have been shown to undergo ring-openings on exposure to B/P FLPs, ${ }^{63}$ nonetheless, the cyclopropanations described herein are to our knowledge the first mediated by a boron-based Lewis acid.

Small Molecule Activation. The potential utility of these cyclopropanation/carboboration products in FLP reactivity was subsequently probed. Combination of the diasteromerically pure cyclopropane derivative $\mathbf{2 d}$ or the 1,4-carboboration product $2 \mathrm{i}$ with the bulky phosphine $t \mathrm{Bu}_{3} \mathrm{P}$ showed no adduct formation. Upon addition of $\mathrm{H}_{2}, \mathrm{NMR}$ data were consistent with the clean activation of $\mathrm{H}_{2}$ in both cases, affording the corresponding phosphonium hydridoborate species 8 and $\mathbf{9}$, respectively (Scheme 7). The spectroscopic data for these products (see SI) are consistent with that previously observed for closely related FLPs. ${ }^{64}$ Similarly, reactions of these FLPs with $\mathrm{CO}_{2}$ (10 bar) cleanly afforded the zwitterionic phosphonium borate $\mathbf{1 0}$ and $\mathbf{1 1}$ (Scheme 7). Again, NMR and IR data (see SI) for these compounds are analogous to previously reported FLP- $\mathrm{CO}_{2}$ adducts. ${ }^{65}$

\section{CONCLUSION}

In summary, the present study has revealed that reactions of $\mathrm{B}\left(\mathrm{C}_{6} \mathrm{~F}_{5}\right)_{3}$ with 1,6-enynes proceed via cyclopropanation and concurrent 1,1-carboboration. Subsequent ring-opening reactions are observed depending on the nature of the olefin substitution, and these afford either cyclopentane or cyclohexane derivatives in which the $\mathrm{C}_{6} \mathrm{~F}_{5}$ and $\mathrm{B}\left(\mathrm{C}_{6} \mathrm{~F}_{5}\right)_{2}$ fragments are 1,4-disposed. Thus, this chemistry exploits the ability of the Lewis acid $\mathrm{B}\left(\mathrm{C}_{6} \mathrm{~F}_{5}\right)_{3}$ to activate alkyne fragments, providing new routes to substituted cyclic organic molecules. The resulting cyclopropane and 1,4-carboration products are also shown herein to participate in FLP activations of $\mathrm{H}_{2}$ and $\mathrm{CO}_{2}$.
Scheme 7. $\mathrm{H}_{2}$ and $\mathrm{CO}_{2}$ Activation with Cyclopropanation/ Carboboration Products

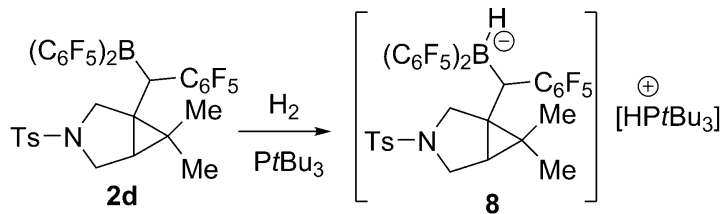

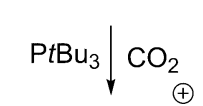

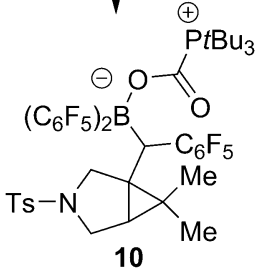

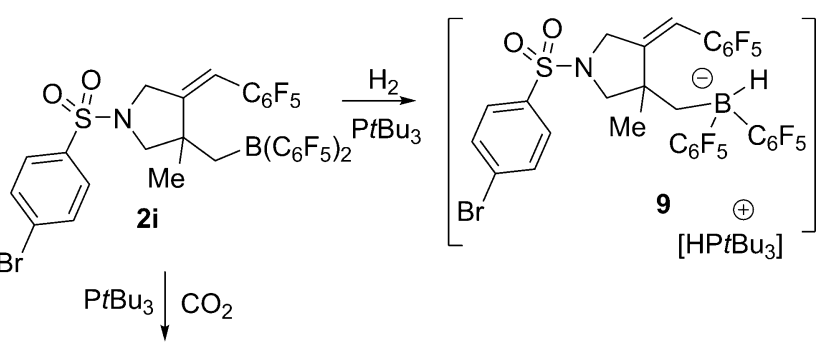<smiles>CCCCC(=O)OB(OC(=S)CC1(C)CN(S(=O)(=O)c2ccc(Br)cc2)C/C1=C/C(F)(F)F)C(F)(F)F</smiles>

It is interesting to note that cyclopropanation products are typically derived from transition metal mediated reactions of enynes. $^{5-12}$ In addition, Pd-mediated borylative enyne cyclizations have been used to install (pinacolato)boron fragments for subsequent cross-couplings. ${ }^{66-68}$ The present work illustrates the ability of the main group Lewis acid $\mathrm{B}\left(\mathrm{C}_{6} \mathrm{~F}_{5}\right)_{3}$ to effect related cyclizations while providing an avenue for the installation of both $\mathrm{C}_{6} \mathrm{~F}_{5}$ and $\mathrm{B}\left(\mathrm{C}_{6} \mathrm{~F}_{5}\right)_{2}$ fragments. It is noteworthy that Erker and co-workers have exploited carboboration products in cross-couplings. ${ }^{28,69}$ Thus, the present chemistry affords a strategy for the synthesis of highly substituted cyclopropanes, cyclopentanes, and cyclohexanes with concurrent carboboration. The potential of this and related chemistry in the synthesis of functionalized complex organic molecules and FLPs continues to be of interest in our laboratories.

\section{ASSOCIATED CONTENT}

\section{Supporting Information}

The Supporting Information is available free of charge on the ACS Publications website at DOI: 10.1021/jacs.5b09311.

Synthetic and spectroscopic data (PDF)

Crystallographic data (CIF)

\section{AUTHOR INFORMATION}

\section{Corresponding Authors}

*mhansmann@ucsd.edu

*dstephan@chem.utoronto.ca 
*hashmi@hashmi.de

\section{Notes}

The authors declare no competing financial interest.

\section{ACKNOWLEDGMENTS}

NSERC of Canada is thanked for financial support. D.W.S. is grateful for the award of a Canada Research Chair. M.M.H. is grateful to the Fonds der Chemischen Industrie for a Chemiefonds scholarship and the Studienstiftung des deutschen Volkes. R.L.M is thankful for a Humboldt Fellowship.

\section{REFERENCES}

(1) Trost, B. M. Angew. Chem., Int. Ed. Engl. 1995, 34, 259-281.

(2) Trost, B. M. Science 1991, 254, 1471-1477.

(3) Trost, B. M.; Tanoury, G. J. J. Am. Chem. Soc. 1988, 110, 16361638

(4) Trost, B. M. Acc. Chem. Res. 1990, 23, 34-42.

(5) Trost, B. M.; Krische, M. J. Synlett 1998, 1998, 1-16.

(6) Trost, B. M.; Toste, F. D.; Pinkerton, A. B. Chem. Rev. 2001, 101, 2067-2096.

(7) Aubert, C.; Buisine, O.; Malacria, M. Chem. Rev. 2002, 102, 813.

(8) Ma, S.; Yu, S.; Gu, Z. Angew. Chem., Int. Ed. 2006, 45, 200-203.

(9) Zhang, L.; Sun, J.; Kozmin, S. A. Adv. Synth. Catal. 2006, 348, 2271-2296.

(10) Jiménez-Núñez, E.; Echavarren, A. M. Chem. Rev. 2008, 108, 3326-3350.

(11) Michelet, V.; Toullec, P. Y.; Genêt, J.-P. Angew. Chem., Int. Ed. 2008, 47, 4268-4315.

(12) Toullec, P.; Michelet, V. In Computational Mechanisms of Au and Pt Catalyzed Reactions; Soriano, E., Marco-Contelles, J., Eds.; Springer: Berlin Heidelberg, 2011; Vol. 302, p 31.

(13) Hashmi, A. S. K.; Frost, T. M.; Bats, J. W. J. Am. Chem. Soc. 2000, 122, 11553-11554.

(14) Power, P. P. Nature 2010, 463, 171-177.

(15) Welch, G. C.; Juan, R. R. S.; Masuda, J. D.; Stephan, D. W. Science 2006, 314, 1124-1126.

(16) Stephan, D. W.; Erker, G. Angew. Chem., Int. Ed. 2010, 49, 4676.

(17) Stephan, D. W.; Erker, G. Angew. Chem., Int. Ed. 2015, 54, 6400-6441.

(18) McCahill, J. S. J.; Welch, G. C.; Stephan, D. W. Angew. Chem., Int. Ed. 2007, 46, 4968-4971.

(19) Dureen, M. A.; Stephan, D. W. J. Am. Chem. Soc. 2009, 131, 8396-8397.

(20) Melen, R. L.; Hansmann, M. M.; Lough, A. J.; Hashmi, A. S. K.; Stephan, D. W. Chem. - Eur. J. 2013, 19, 11928-11938.

(21) Hansmann, M. M.; Melen, R. L.; Rominger, F.; Hashmi, A. S. K.; Stephan, D. W. J. Am. Chem. Soc. 2014, 136, 777-782.

(22) Hansmann, M. M.; Melen, R. L.; Rominger, F.; Hashmi, A. S. K.; Stephan, D. W. Chem. Commun. 2014, 50, 7243-7245.

(23) Chen, C.; Harhausen, M.; Liedtke, R.; Bussmann, K.; Fukazawa, A.; Yamaguchi, S.; Petersen, J. L.; Daniliuc, C. G.; Frohlich, R.; Kehr, G.; Erker, G. Angew. Chem., Int. Ed. 2013, 52, 5992-5996.

(24) Melen, R. L. Chem. Commun. 2014, 50, 1161-1174.

(25) Lee, S. I.; Chatani, N. Chem. Commun. 2009, 371-384.

(26) Bour, C.; Gandon, V. Synlett 2015, 26, 1427.

(27) Jiang, C. F.; Blacque, O.; Berke, H. Organometallics 2010, 29, $125-133$.

(28) Chen, C.; Kehr, G.; Fröhlich, R.; Erker, G. J. Am. Chem. Soc. 2010, 132, 13594-13595.

(29) Kehr, G.; Erker, G. Chem. Commun. 2012, 48, 1839-1850.

(30) Chen, C.; Eweiner, F.; Wibbeling, B.; Fröhlich, R.; Senda, S.; Ohki, Y.; Tatsumi, K.; Grimme, S.; Kehr, G.; Erker, G. Chem. - Asian J. 2010, 5, 2199-2208.

(31) Chen, C.; Voss, T.; Fröhlich, R.; Kehr, G.; Erker, G. Org. Lett. 2011, 13, 62-65.
(32) Ekkert, O.; Kehr, G.; Fröhlich, R.; Erker, G. Chem. Commun. 2011, 47, 10482-10484.

(33) Ekkert, O.; Kehr, G.; Fröhlich, R; Erker, G. J. Am. Chem. Soc. 2011, 133, 4610-4616.

(34) Ekkert, O.; Tuschewitzki, O.; Daniliuc, C. G.; Kehr, G.; Erker, G. Chem. Commun. 2013, 49, 6992-6994.

(35) Feldhaus, P.; Kehr, G.; Fröhlich, R.; Daniliuc, C. G.; Erker, G. Z. Naturforsch., B: J. Chem. Sci. 2013, 68, 666-674.

(36) Liedtke, R.; Harhausen, M.; Fröhlich, R.; Kehr, G.; Erker, G. Org. Lett. 2012, 14, 1448-1451.

(37) Mobus, J.; Bonnin, Q.; Ueda, K.; Fröhlich, R.; Itami, K.; Kehr, G.; Erker, G. Angew. Chem., Int. Ed. 2012, 51, 1954-1957.

(38) Tsao, F. A.; Lough, A. J.; Stephan, D. W. Chem. Commun. 2015, 51, 4287-4289.

(39) Tsao, F. A.; Stephan, D. W. Dalton Trans. 2015, 44, 71-74.

(40) Liedtke, R.; Tenberge, F.; Daniliuc, C. G.; Kehr, G.; Erker, G. J. Org. Chem. 2015, 80, 2240-2248.

(41) Ge, F.; Kehr, G.; Daniliuc, C. G.; Erker, G. Organometallics 2015, 34, 229-235.

(42) Eller, C.; Kehr, G.; Daniliuc, C. G.; Erker, G. Chem. Commun. 2015, 51, 8436-8438.

(43) Eller, C.; Kehr, G.; Daniliuc, C. G.; Stephan, D. W.; Erker, G. Chem. Commun. 2015, 51, 7226-7229.

(44) Cade, I. A.; Ingleson, M. J. Chem. - Eur. J. 2014, 20, 1287412880.

(45) Devillard, M.; Brousses, R.; Miqueu, K.; Bouhadir, G.; Bourissou, D. Angew. Chem., Int. Ed. 2015, 54, 5722-5726.

(46) Melen, R. L.; Wilkins, L. C.; Kariuki, B. M.; Wadepohl, H.; Gade, L. H.; Hashmi, A. S. K.; Stephan, D. W.; Hansmann, M. M. Organometallics 2015, 34, 4127-4137.

(47) Feldmann, A.; Iida, A.; Fröhlich, R.; Yamaguchi, S.; Kehr, G.; Erker, G. Organometallics 2012, 31, 2445-2451.

(48) Feldmann, A.; Kehr, G.; Daniliuc, C. G.; Muck-Lichtenfeld, C.; Erker, G. Chem. - Eur. J. 2015, 21, 12456-12464.

(49) Warner, A. J.; Lawson, J. R.; Fasano, V.; Ingleson, M. J. Angew. Chem., Int. Ed. 2015, 54, 11245.

(50) Dorel, R; Echavarren, A. M. J. Org. Chem. 2015, 80, 7321.

(51) Brooner, R. E. M.; Brown, T. J.; Widenhoefer, R. A. Angew. Chem., Int. Ed. 2013, 52, 6259.

(52) Fürstner, A.; Morency, L. Angew. Chem., Int. Ed. 2008, 47, 5030-5033.

(53) Nieto-Oberhuber, C.; López, S.; Jiménez-Núñez, E.; Echavarren, A. M. Chem. - Eur. J. 2006, 12, 5916.

(54) Soriano, E.; Marco-Contelles, J. J. Org. Chem. 2005, 70, 93459353.

(55) Fürstner, A.; Szillat, H.; Gabor, B.; Mynott, R. J. Am. Chem. Soc. 1998, 120, 8305-8314.

(56) Chatani, N.; Kataoka, K.; Murai, S.; Furukawa, N.; Seki, Y. J. Am. Chem. Soc. 1998, 120, 9104.

(57) Chen, J.; Reibenspies, J.; Derecskei-Kovacs, A.; Burgess, K. Chem. Commun. 1999, 2501-2502.

(58) Hsee, L. C.; Sardella, D. J. Magn. Reson. Chem. 1990, 28, 688692.

(59) Hierso, J.-C. Chem. Rev. 2014, 114, 4838-4867.

(60) Zhao, X.; Stephan, D. W. J. Am. Chem. Soc. 2011, 133, 1244812450 .

(61) Hill, E. A.; Park, Y.-W. J. Organomet. Chem. 1988, 356, 1-16.

(62) Pei, W.; Krauss, I. J. J. Am. Chem. Soc. 2011, 133, 18514-18517.

(63) Morton, J. G. M.; Dureen, M. A.; Stephan, D. W. Chem. Commun. 2010, 46, 8947-8949.

(64) Welch, G. C.; Stephan, D. W. J. Am. Chem. Soc. 2007, 129, $1880-1881$

(65) Mömming, C. M.; Otten, E.; Kehr, G.; Fröhlich, R.; Grimme, S.; Stephan, D. W.; Erker, G. Angew. Chem., Int. Ed. 2009, 48, 6643-6646.

(66) Marco-Martínez, J.; Buñuel, E.; López-Durán, R.; Cárdenas, D. J. Chem. - Eur. J. 2011, 17, 2734-2741.

(67) Marco-Martínez, J.; López-Carrillo, V.; Buñuel, E.; Simancas, R.; Cárdenas, D. J. J. Am. Chem. Soc. 2007, 129, 1874-1875. 
(68) Pardo-Rodríguez, V.; Marco-Martínez, J.; Buñuel, E.; Cárdenas, D. J. Org. Lett. 2009, 11, 4548-4551.

(69) Chen, C.; Voss, T.; Fröhlich, R.; Kehr, G.; Erker, G. Org. Lett. 2011, 13, 62-65. 